\title{
natureINSIGHT
}

\section{SILICON ELECTRONICS AND BEYOND}

17 November 2011 / Vol 479 / Issue No 7373

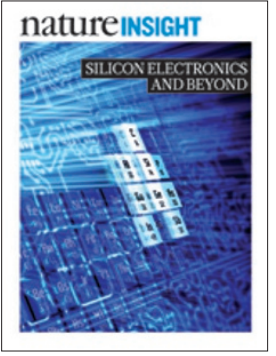

Cover illustration by

Nik Spencer

(background

image: H. Jonsson/

iStockphoto)

\section{Editor, Nature}

Philip Campbell

Publishing

Nick Campbell

Insights Editor

Karl Ziemelis

Production Editor

Nicola Bailey

Senior Art Editor

Kelly Buckheit Krause

Art Editor

Nik Spencer

Sponsorship

Gerard Preston

Production

Emilia Orviss

Marketing

Elena Woodstock

Hannah Phipps

Editorial Assistant

Hazel Mayhew $\longrightarrow$ urs is an age of fast-moving information and computer technology. This progress is being driven for a good part by the microelectronics industry, which has been delivering faster and more efficient computers at a remarkably consistent pace. Since the integrated circuit, or silicon chip, was invented in the late 1950s, the number of transistors on a chip has doubled roughly every 18 months - an observation known as Moore's law - so microprocessors can now contain more than two billion transistors.

This achievement is due largely to the design of the classic silicon transistor, which allowed the scaling down of transistors while also improving speed and energy consumption. These triple benefits led to the rise of affordable personal computers in the 1980s and, more recently, to mobile computing technologies such as laptops, smart phones and tablets.

However, transistors cannot scale down indefinitely, and they are now so small that further shrinking would compromise performance. The microelectronics industry is therefore looking beyond the classic silicon transistor to secure the future of a new generation of computers. There is certainly no shortage of new device concepts, but given the existing wide-scale expertise and infrastructure, the best candidates, at least in the short term, are likely to be those that can be integrated within conventional chip technology.

This Insight reviews six promising approaches: some are already at or near the point of manufacturing; others may take another decade (or two). As is imperative for any new technology, the potential environmental impact needs to be assessed, and a Perspective offers some thoughts on such implications.

What is clear is that the silicon transistor is not going to be replaced very soon. However, the integration of new devices with conventional silicon electronics will open up a diverse range of computer applications, from ubiquitous low-power devices to quantum information processors. Silicon-based electronics will continue to drive the information revolution for the foreseeable future.

Liesbeth Venema Senior Editor

\section{CONTENTS}

\section{REVIEWS}

310 Multigate transistors as the future of classical metal-oxide-semiconductor field-effect transistors

Isabelle Ferain, Cynthia A Colinge \& Jean-Pierre Colinge

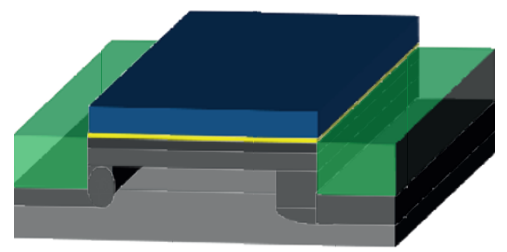

317 Nanometre-scale electronics with III-V compound semiconductors Jesús A del Alamo

324 Academic and industry research progress in germanium nanodevices Ravi Pillarisetty

329 Tunnel field-effect transistors as energy-efficient electronic switches Adrian M lonescu \& Heike Riel

338 A role for graphene in silicon-based semiconductor devices Kinam Kim, Jae-Young Choi, Taek Kim, Seong-Ho Cho \& Hyun-Jong Chung

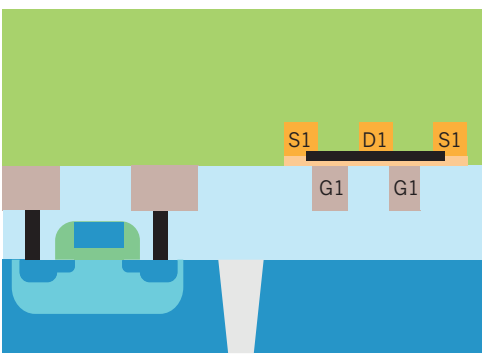

345 Embracing the quantum limit in silicon computing John J L Morton, Dane R McCamey, Mark A Eriksson \& Stephen A Lyon

\section{PERSPECTIVE}

354 Environmental effects of information and communications technologies Eric Williams 